\title{
Article \\ Endoscopic Resection for Gastric Subepithelial Tumor with Backup Laparoscopic Surgery: Description of a Single-Center Experience
}

\author{
Wei-Jung Chang ${ }^{1}{ }^{(\mathbb{C}}$, Lien-Cheng Tsao ${ }^{1}$, Hsu-Heng Yen ${ }^{2,3,4,5}$, , Chia-Wei Yang ${ }^{2}$, Joseph Lin ${ }^{1}$ (D) \\ and Kuo-Hua Lin ${ }^{1, *}$ \\ 1 Department of General Surgery, Changhua Christian Hospital, Changhua 500, Taiwan; \\ microvillis@gmail.com (W.-J.C.); yannick881009@gmail.com (L.-C.T.); joseph.lin27@gmail.com (J.L.) \\ 2 Division of Gastroenterology, Changhua Christian Hospital, Changhua 500, Taiwan; \\ blaneyen@gmail.com (H.-H.Y.); 97601@cch.org.tw (C.-W.Y.) \\ 3 Artificial Intelligence Development Center, Changhua Christian Hospital, Changhua 500, Taiwan \\ 4 College of Medicine, National Chung Hsing University, Taichung 400, Taiwan \\ 5 Department of Electrical Engineering, Chung Yuan University, Taoyuan 320, Taiwan \\ * Correspondence: $120380 @$ cch.org.tw
}

Citation: Chang, W.-J.; Tsao, L.-C.; Yen, H.-H.; Yang, C.-W.; Lin, J.; Lin, K.-H. Endoscopic Resection for Gastric Subepithelial Tumor with Backup Laparoscopic Surgery: Description of a Single-Center Experience. J. Clin. Med. 2021, 10, 4423. https://doi.org/10.3390/ jcm10194423

Academic Editors:

Anastasios Koulaouzidis and Matthias Biebl

Received: 13 August 2021

Accepted: 24 September 2021

Published: 27 September 2021

Publisher's Note: MDPI stays neutral with regard to jurisdictional claims in published maps and institutional affiliations.

Copyright: (c) 2021 by the authors. Licensee MDPI, Basel, Switzerland. This article is an open access article distributed under the terms and conditions of the Creative Commons Attribution (CC BY) license (https:// creativecommons.org/licenses/by/ $4.0 /)$.

\begin{abstract}
The aim of this study was to analyze patients who underwent endoscopic resection (ER) for gastric subepithelial tumors (SETs) with a high probability of surgical intervention. Between January 2013 and January 2021, 83 patients underwent ER at the operation theater and 27 patients $(32.5 \%)$ required backup surgery mainly due to incidental perforation or uncontrolled bleeding despite endoscopic repairing. The tumor was predominantly located in the upper-third stomach $(81 \%)$ with a size $\leq 2 \mathrm{~cm}(69.9 \%)$ and deep to the muscularis propria (MP) layer $(92.8 \%)$ but there were no significant differences between two groups except tumor exophytic growth as a risk factor in the surgery group $(37 \%$ vs. $0 \%, p<0.0001)$. Patients in the ER-only group had shorter durations of procedure times (60 $\mathrm{min}$ vs. $185 \mathrm{~min}, p<0.0001$ ) and lengths of stay ( 5 days vs. 7 days, $p<0.0001$ ) but with a higher percentage of overall morbidity graded III ( $0 \%$ vs. $7.1 \%, p=0.1571)$. After ER, five patients $(6 \%)$ had delayed perforation and two $(2.4 \%)$ required emergent laparoscopic surgery. Neither recurrence nor gastric stenosis was reported during long-term surveillance. Here, we provide a minimally invasive strategy of endoscopic resection with backup laparoscopic surgery for gastric SETs.
\end{abstract}

Keywords: gastric subepithelial tumor; endoscopic resection; laparoscopic surgery; gastrointestinal stromal tumor; delayed perforation

\section{Introduction}

With advances in upper endoscopy and its wide availability, gastric subepithelial tumors (SETs) are occasionally detected during health examinations or cancer screening tests. Gastric SETs are classified as neoplastic lesions that are either malignant or have malignant potential, including gastrointestinal stromal tumors (GISTs), carcinoid tumors, lymphomas, glomus tumors, and lymphangiomas and non-neoplastic lesions such as leiomyomas, schwannomas, inflammation, cysts, and ectopic pancreas [1,2]. The management of subepithelial lesions was tailored according to tumor characteristics, symptoms, comorbidities, and patient compliance with long-term surveillance. GISTs are the most common type of gastric SETs with origin in the muscularis propria (MP) layer [3], and surgical resection is recommended when the size is larger than 20-30 $\mathrm{mm} \mathrm{[1,4-6]} \mathrm{because} \mathrm{of} \mathrm{their} \mathrm{malignant}$ potential. A combination of endoscopic and laparoscopic techniques was developed to achieve precise localization, minimal resection, and functional preservation [7] with the advantages of both. In Japan, laparoscopic and luminal endoscopic cooperative surgery 
(LECS), developed by a multidisciplinary team since 2008 [8-11], has been approved for national insurance coverage to resect gastric SETs.

The management of small $(\leq 2 \mathrm{~cm})$, asymptomatic gastric subepithelial tumors (SETs) remains inconclusive and the patients' compliance for long-term follow-up was poor [12] since the necessity of regular endoscopic ultrasound (EUS) surveillance was recommended [1]. With improvements in endoscopic techniques and devices [13-19], endoscopic submucosal dissection (ESD) has been tailored to the management of gastric SETs according to tumor characteristics [20-26], not only for diagnostic accuracy but also for therapeutic resection. However, endoscopic resection for gastric SETs originating from the MP layer carries a relatively high risk of complicated perforation in $\mathrm{R} 0$ attempts for tumor resection. Perforation or bleeding is encountered at rates ranging from $0 \%$ to $15.6 \%$ and $0 \%$ to $8.2 \%$, respectively, even with endoscopic hemostasis or when clips are used $[17,20-22,27,28]$. Cooperation between the endoscopist and the surgeon could provide a safe environment with backup laparoscopic surgery if endoscopic resection (ER) fails. In this study, we aimed to analyze patients who underwent endoscopic resection for gastric SETs with a high probability of surgical intervention and to outline a feasible procedure with backup surgery.

\section{Materials and Methods}

\subsection{Study Population}

In this retrospective study, we examined the electronic medical records of 86 patients (three patients were later excluded due to anatomic changes) who underwent endoscopic resection for gastric SETs at the operation theater from a single medical center in Taiwan between January 2013 and January 2021. The study was approved by the Institutional Review Board of Changhua Christian Hospital (Document no. 201022 and no. 210202), and this retrospective study waived the need for informed consent.

Complete resection of gastric subepithelial tumors (SETs) is indicated for tumors $>2 \mathrm{~cm}$ that are symptomatic with malignant features that are increasing in size during surveillance, or with patient's preference [1,2,4-6]. For patients who declined either periodical surveillance of their SETs or laparoscopic resection, they received endoscopic resection in the operation theater with the backup laparoscopic surgery due to a high risk of incidental gastric perforation or uncontrolled bleeding. The high probability of surgical interventions included the following situations: (1) tumor located in the upper-third stomach due to a relatively thin wall and difficulty of endoscopic angulation; (2) tumor located at the anterior wall of the body, where air leakage easily occurred with difficult endoscopic repair; (3) tumor located deep to the MP layer or subserosa; and (4) tumor growth with an exophytic pattern. In total, 83 patients who underwent endoscopic intervention in the operation theater were included. Three patients with anatomic changes in the stomach due to previous operations were excluded, with two patients receiving subtotal gastrectomy and one who underwent esophagectomy.

\subsection{Procedure}

All patients received general anesthesia and prophylactic antibiotic (cefazolin $1 \mathrm{~g}$ ) by intravenous infusion in the supine position at the operation theater. The gastroenterologists inserted an endoscope (GIF-H260Z or GIF-2TQ260M, Olympus, Tokyo, Japan) into the stomach of the patient and identified the tumor location. Two types of endoscopes were chosen depending on the location of the gastric SET: GIF-2TQ260M for those in the cardia and GIF-H260Z for those in the body or antrum. Endoscopic resection was performed around the tumor with a $0.5-\mathrm{cm}$ margin by submucosal injection with glycerin, mucosal incision, and submucosal dissection. The DualKnife (KD-650L, Olympus, Tokyo, Japan) with an additional ITknife nano electrosurgical knife (KD-612L, Olympus, Tokyo, Japan) or Coagrasper Hemostatic Forceps (FD-412LR, Olympus, Tokyo, Japan) was used for endoscopy, depending on the patients' preferences and budgets. The endoscopists attempted to remove the gastric SETs with R0 resection by preserving the tumor capsule like GIST or leiomyoma. Occasionally, piecemeal resection technique aimed to achieve R1 resection if 
R0 resection was not feasible in the situations of uncontrolled bleeding, large tumor size, or infiltrative tumor border with its surrounding gastric tissue, like aberrant pancreas or lipoma. In cases involving incidental gastric perforation or uncontrolled bleeding that could not be resolved by endoscopic clips or hemostasis, general surgeons took over the procedure and completed the procedure with laparoscopic wedge gastrectomy.

The patient was placed in the reverse Trendelenburg position. The general surgeon stood on the patient's right side with an assistant on the contralateral side. A camera port was inserted into the umbilicus using the Hasson open technique to create a pneumoperitoneum with a pressure of 10-12 $\mathrm{mmHg}$. Two additional ports (one 12-mm port and one 5 -mm port) were inserted into the midclavicular line of the left-upper and right-upper abdomen with slight modifications depending on the lesion site. Tumors were easily identified due to incidental perforation by endoscopic resection (Figure 1). If the tumor was on the posterior stomach, the gastrocolic ligament was divided using a vessel-sealing device (LigaSure, LF1837, Covidien, Minneapolis, MN, USA) to flip the stomach and localize the lesions. The surgeon completed tumor resection with a 1-cm margin and closed the perforation site longitudinally to the stomach using a laparoscopic stapling device (Echelon Flex Endopath SC60A, Ethicon, USA) (Figure 2). The laparoscopic stapling device was adjusted in the transverse direction of the stomach if the tumor was located on the lesser curvature side or cardia to avoid stenosis. The staple line was further reinforced by continuing Lambert suturing with an absorbable wound closure device, 3-0 V-Loc (VLOCL0604, Covidien, USA) (Figure 3). The camera port was changed to the left-upper port in cases where it was difficult to locate the tumor or in cases of limited adjustment direction for stapling devices. The tumor was retrieved (Figure 4) using a specimen bag, and the absence of bleeding was confirmed before a drainage tube was placed near the perforation site or in the left subphrenic area.

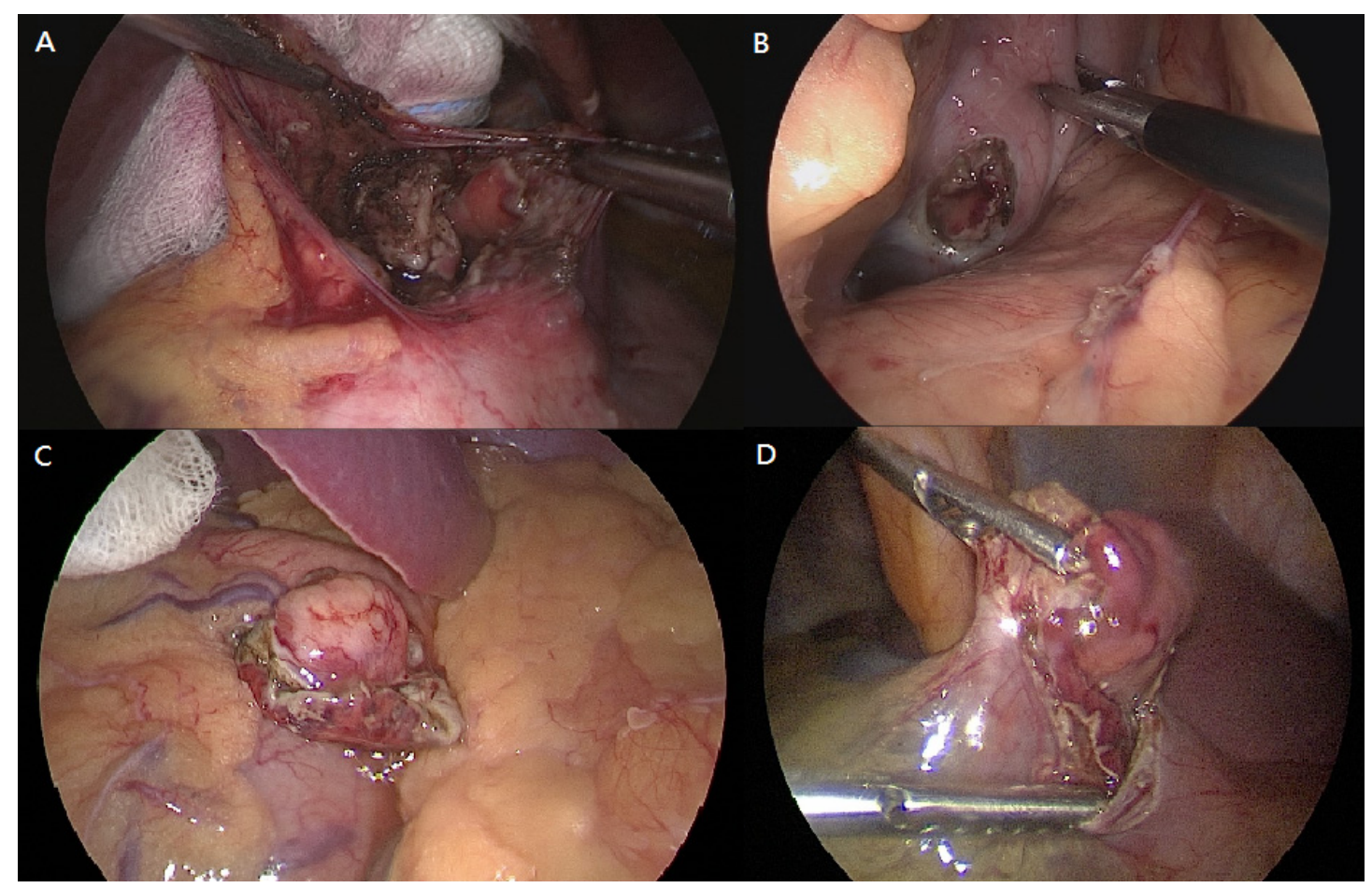

Figure 1. Different perforation sites of the stomach after endoscopic resection: (A) at the cardia, (B) at the posterior fundus, (C) at the greater curvature of fundus with incomplete resection, (D) at the anterior antrum with incomplete resection. 


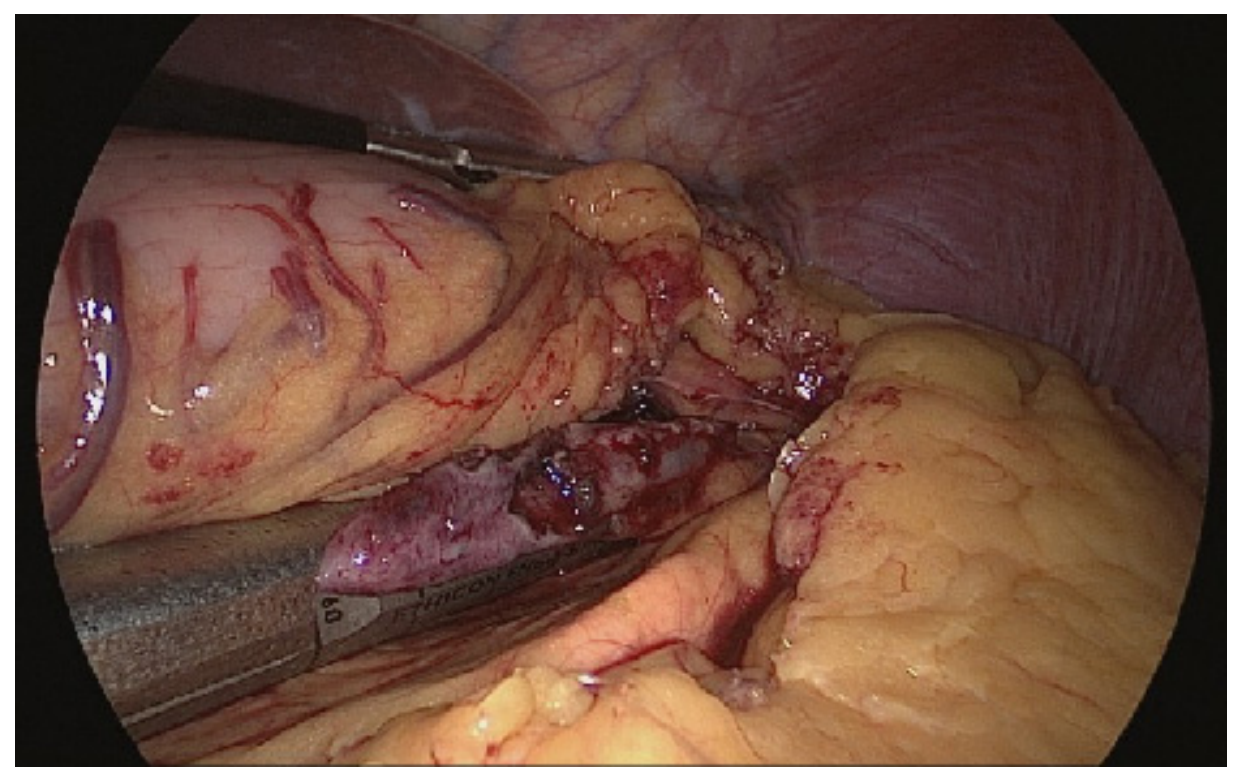

Figure 2. Laparoscopic stapling device used for closure of the gastric perforation site at the posterior fundus.

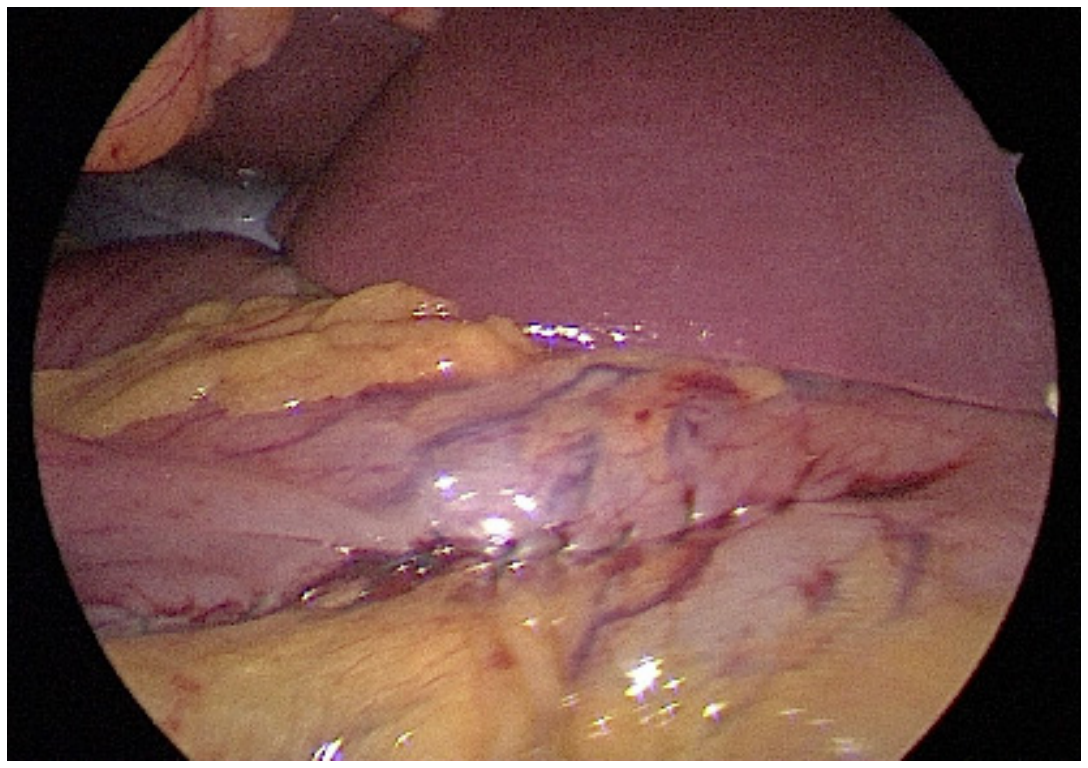

Figure 3. Laparoscopic reinforced suturing over the stapling line after closure of the perforation site at the anterior antrum.

\subsection{Clinicopathological Factors}

The clinical characteristics of the patients included age, sex, procedure time, length of hospital stay, and overall morbidity. All complications within 30 days utilized the revised Clavien-Dindo classification, with grades III-V considered clinically relevant morbidity [29]. The clinicopathological characteristics of the tumors were analyzed based on location, size, layer of tumor depth, pathological categories of malignant or malignant potential, and benign diseases. The location of the gastric SETs was classified by dividing the stomach into three equal sections (upper, middle, and lower third) or four equal sections (anterior wall, posterior wall, lesser curvature, and greater curvature). The diameter of the tumor was classified as $\leq 2 \mathrm{~cm}$ or $>2 \mathrm{~cm}$. Endoscopic ultrasonography was performed to determine the layer of tumor depth from the submucosal (SM) or MP layer. All patients received postoperative care with intravenous fluid supplement, pain relief, and intravenous 
esomeprazole (40 mg/day). Patients were allowed to attempt an oral diet on postoperative day (POD) 3 with an increasing amount as tolerated. Patients were discharged if they tolerated oral medication. Delayed perforation was identified after completion of ER with the sudden onset of symptoms related to pneumoperitoneum, as confirmed by an image survey. A further endoscopy was arranged 3 months after the surgery as a follow-up.

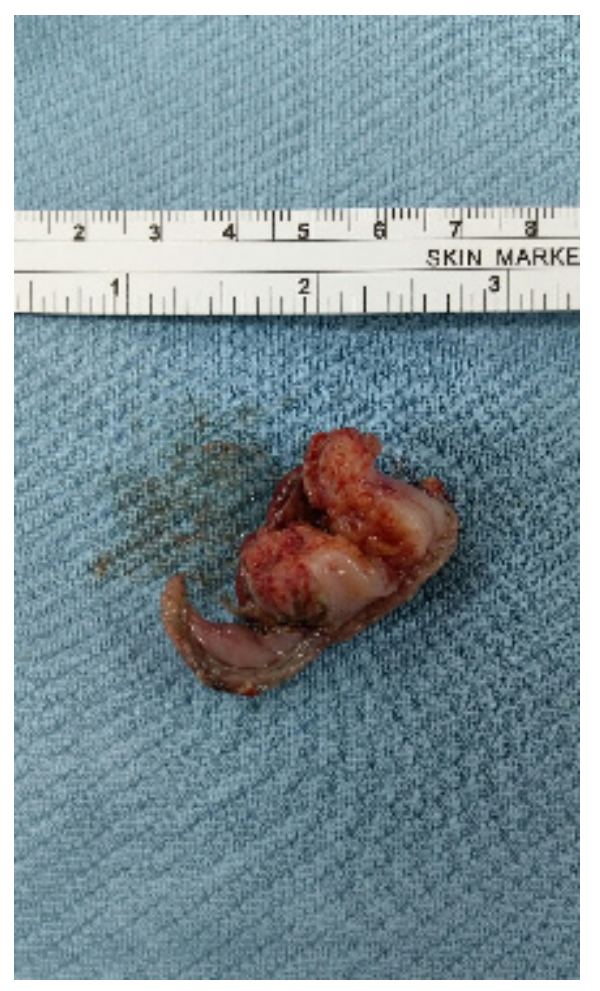

Figure 4. Gastric subepithelial tumor retrieved from specimen bag after laparoscopic endoscopic cooperative surgery.

All specimens were analyzed by histological examination at the Department of Pathology at Changhua Christian Hospital. Immunohistochemistry analysis was performed with common markers such as CD117 (c-kit), CD34, DOG-1, smooth muscle actin, and S100. The c-kit protein is highly sensitive and specific for GISTs, whereas CD34 and DOG-1 are expressed in approximately $80 \%$ of GISTs. Positive staining for smooth muscle actin indicates the presence of leiomyoma or glomus tumor, while the presence of S100 indicates neural origin or schwannoma. GISTs are further divided by risk according to the National Institutes of Health-Fletcher classification after evaluation of the size and mitotic index by hematoxylin and eosin staining.

\subsection{Statistical Analysis}

Patient data were expressed as median with interquartile range (IQR) and categorical variables with percentage. A Mann-Whitney U-test was used to compare the differences in continuous variables, while a Chi-squared test was used to compare the differences in categorical variables. Statistical significance was defined as $p<0.05$. All statistical analyses were performed on a personal computer using MedCalc for Windows version 20 (MedCalc Software, Ostend, Belgium).

\section{Results}

A total of 83 patients were enrolled for the study, of which $56(67.5 \%)$ underwent ER-only for gastric SETs at the operation theater, while 27 (32.5\%) underwent backup laparoscopic surgery. Among those receiving backup surgery, 26 cases were indicated due to incidental perforation $(31.3 \%)$, with four cases of additional bleeding $(4.8 \%)$ and one 
case was due to ill-defined tumor margins (1.2\%). Overall, the tumor was predominantly located in the upper-third stomach (81\%) with a size $\leq 2 \mathrm{~cm}(69.9 \%)$ and deep to the MP layer (92.8\%). None of the factors, including age, sex, tumor location, tumor size, layer of tumor depth, whether pathologically proven malignancy or malignancy potential, and benign lesions, was statistically associated with the two resection methods. Although a higher percentage of tumor size $\leq 2 \mathrm{~cm}$ in the ER-only group (75\% vs. $59.3 \%, p=0.1455)$ and a higher percentage of tumor depth to the MP layer in the surgery group (100\% vs. $89.3 \%, p=0.0792$ ) were observed, there did not exist a statistical difference. The ER-only group had shorter duration of procedure times (60 min vs. $185 \mathrm{~min}, p<0.0001$ ) and length of stay ( 5 days vs. 7 days, $p<0.0001$ ) but also a higher percentage of overall morbidity, with grade III occurring, which showed no significant difference $(7.1 \%$ vs. $0 \%, p=0.1571)$ In the surgery group, a higher percentage of tumors with exophytic growth was noted (37\% vs. $0 \%, p<0.0001)$ (Table 1$)$.

Table 1. Patient characteristics and peri-procedure parameters.

\begin{tabular}{|c|c|c|c|c|c|}
\hline \multirow[b]{2}{*}{ Age, years } & \multicolumn{2}{|c|}{$\begin{array}{c}\text { ESD Only } \\
n=56\end{array}$} & \multicolumn{2}{|c|}{$\begin{array}{c}\text { Backup Surgery } \\
n=27\end{array}$} & \multirow{2}{*}{$\begin{array}{c}p \text { Value } \\
0.4222\end{array}$} \\
\hline & 54.5 & $(48.0-63.0)$ & 56.0 & $(50.5-63.3)$ & \\
\hline Male gender & 26 & $(46.4)$ & 9 & $(33.3)$ & 0.2606 \\
\hline Tumor location & & & & & 0.8634 \\
\hline Upper & 45 & $(80.4)$ & 23 & $(85.2)$ & \\
\hline Middle & 3 & $(5.4)$ & 1 & $(3.7)$ & \\
\hline Low & 8 & $(14.2)$ & 3 & $(11.1)$ & \\
\hline Tumor size & & & & & 0.1455 \\
\hline$\leq 2 \mathrm{~cm}$ & 42 & $(75.0)$ & 16 & $(59.3)$ & \\
\hline$>2 \mathrm{~cm}$ & 14 & $(25.0)$ & 11 & $(40.7)$ & \\
\hline Layer of tumor depth & & & & & 0.0792 \\
\hline Submucosa & 6 & $(10.7)$ & 0 & $(0.0)$ & \\
\hline Muscularis propria & 50 & (89.3) & 27 & $(100.0)$ & \\
\hline Exophytic growth & 0 & $(0.0)$ & 10 & $(37.0)$ & $<0.0001$ * \\
\hline Procedure time, mins & 60.0 & $(40.0-90.0)$ & 185.0 & $(152.0-236.8)$ & $<0.0001$ * \\
\hline Length of stay, days & 5 & $(4-6)$ & 7 & $(7-8)$ & $<0.0001$ * \\
\hline $\begin{array}{l}\text { Clavien } \geq \text { III } \\
\text { complication }\end{array}$ & 4 & (7.1) & 0 & $(0.0)$ & 0.1571 \\
\hline Pathology & & & & & 0.4387 \\
\hline $\begin{array}{l}\text { Malignant/malignant } \\
\text { potential }\end{array}$ & 26 & $(46.4)$ & 15 & (55.6) & \\
\hline Benign & 30 & $(53.6)$ & 12 & $(44.4)$ & \\
\hline
\end{tabular}

Among those patients with complications, two patients were graded IIIa, with one case of gastric ulcer bleeding receiving endoscopic hemostasis on POD 9 and another case of delayed perforation. Another two patients with grade IIIlb delayed perforation underwent emergent laparoscopic surgery. Both cases were discharged on postoperative day 6 with uneventful recovery. No mortality was recorded during the follow-up period. Overall, five cases of delayed perforation (6\%) are shown in Table 2. Among them, four patients had tumors located in the upper-third stomach and three patients had tumors in the anterior wall. All patients received endoclipping for suspected endoscopic perforation. Among them, two patients recovered from conservative treatment $(2.4 \%)$, one case required radiological intervention (1.2\%), and two patients underwent emergent laparoscopic surgery $(2.4 \%)$. 
Table 2. Clinical data of five cases with delayed perforation after ESD for gastric subepithelial tumors.

\begin{tabular}{|c|c|c|c|c|c|c|c|c|c|c|c|c|}
\hline Case & Age & Sex & $\begin{array}{l}\text { Tumor } \\
\text { Location }\end{array}$ & $\begin{array}{l}\text { Size } \\
(\mathrm{cm})\end{array}$ & Depth & $\begin{array}{c}\text { ESD } \\
\text { Time } \\
\text { (minutes) }\end{array}$ & $\begin{array}{c}\text { Time to } \\
\text { Diagnosis } \\
\text { (hours) }\end{array}$ & $\begin{array}{l}\text { Symptom } \\
\text { /Signs }\end{array}$ & $\begin{array}{l}\text { Image } \\
\text { Survey }\end{array}$ & Severity & Management & $\begin{array}{l}\text { LOS } \\
\text { (days) }\end{array}$ \\
\hline 1 & 56 & $\mathrm{~F}$ & $\mathrm{U}$, les & 1.0 & SM & 60 & 6 & Fever & $\begin{array}{l}\text { CXR: Bil. } \\
\text { subphrenic } \\
\text { air }\end{array}$ & Grade I & $\begin{array}{l}\text { Conservative } \\
\text { care }\end{array}$ & 8 \\
\hline 2 & 43 & $\mathrm{~F}$ & $\mathrm{~L}$, ant & 2.6 & SM & 90 & 8 & $\begin{array}{l}\text { Localized } \\
\text { abd. pain }\end{array}$ & $\begin{array}{l}\text { CT: } \\
\text { Pneumoperi- } \\
\text { toneum with } \\
\text { few ascites }\end{array}$ & Grade I & $\begin{array}{l}\text { Conservative } \\
\text { care }\end{array}$ & 8 \\
\hline 3 & 69 & $\mathrm{~F}$ & $\mathrm{U}$, ant & 0.4 & MP & 33 & 47 & $\begin{array}{l}\text { Localized } \\
\text { abd. pain }\end{array}$ & $\begin{array}{c}\text { CXR: Bil } \\
\text { subphrenic } \\
\text { air }\end{array}$ & Grade III & $\begin{array}{l}\text { Sono- } \\
\text { guided } \\
\text { aspiration }\end{array}$ & 8 \\
\hline 4 & 42 & $\mathrm{M}$ & $\mathrm{U}$, ant & 0.5 & MP & 20 & 6 & Hematemesis & $\begin{array}{c}\text { CT: } \\
\text { Pneumoperi- } \\
\text { toneum with } \\
\text { internal } \\
\text { bleeding }\end{array}$ & $\begin{array}{l}\text { Grade } \\
\text { IIIlb }\end{array}$ & $\begin{array}{l}\text { Laparoscopic } \\
\text { gastrorrha- } \\
\text { phy }\end{array}$ & 8 \\
\hline 5 & 52 & $\mathrm{M}$ & $\mathrm{U}$, post & 0.5 & MP & 40 & 24 & $\begin{array}{l}\text { Fever with } \\
\text { peritonitis }\end{array}$ & $\begin{array}{l}\text { CT: } \\
\text { pneumoperi- } \\
\text { toneum with } \\
\text { few ascites }\end{array}$ & $\begin{array}{l}\text { Grade } \\
\text { IIIlb }\end{array}$ & $\begin{array}{l}\text { Laparoscopic } \\
\text { gastrorrha- } \\
\text { phy }\end{array}$ & 9 \\
\hline
\end{tabular}

F: female; M: male; U: upper third; L: lower third; Les: lesser curvature; Ant: anterior; Post: posterior; SM: submucosa; MP: Muscularis propia; ESD: endoscopic submucosal dissection; CXR: chest X-ray; CT: computed tomography; LOS: length of stay. Complication severity was graded according to Clavien-Dindo classification.

For pathologic diagnosis, there were no significant differences in the malignancy or malignancy potential and benign lesions between the two groups. The detailed pathology is listed individually (Table 3). The most common type of malignant group was GIST (47\%), followed by neuroendocrine tumor (1.2\%), and hyperplastic polyps with focal high-grade dysplasia (1.2\%). All tumors achieved R0 resection with a safe margin. According to the NIH classification [30], the recurrence risk of GISTs was categorized into very-low-risk $(56.4 \%)$, low-risk $(30.8 \%)$, and intermediate-risk (12.8\%) groups. Patients diagnosed with GIST underwent long-term surveillance with a mean duration of 19.5 months, and no recurrence was detected. In the case of a neuroendocrine tumor Grade 1, the patient received further gastrectomy and adjuvant chemotherapy. No recurrence was noted during a 52-month follow-up period.

The most common benign group was leiomyoma (37.4\%) followed by ectopic pancreas (3.6\%), calcifying fibrous tumor (2.4\%), lipoma (1.2\%), inflammatory fibroid polyp (1.2\%), gastritis cystica profunda $(1.2 \%)$, plexiform fibromyxoma $(1.2 \%)$, elastofibroma $(1.2 \%)$, and pyloric gland adenoma $(1.2 \%)$.

The location of the tumors and the percentage of patients requiring surgery, including two cases of delayed perforation receiving surgery, are depicted in Figure 5. Most tumors were in the upper-third stomach $(n=68,81.9 \%)$, comprising the posterior wall $(n=27,32.5 \%)$, cardia $(n=19,22.9 \%)$, anterior wall $(n=15,18.1 \%)$, and greater curvature $(\mathrm{n}=7,8.4 \%)$ in descending order. Fewer tumors were in the lower-third $(n=11,13.3 \%)$ and middle-third stomach $(n=4,4.8 \%)$. The overall surgery rate was $34.9 \%$, and in descending order were upper $(36.8 \%)$, middle $(25 \%)$, and lower $(27.3 \%)$. The highest surgery rate was noted in the anterior wall of the lower-third stomach $(60 \%)$ followed by the lesser curvature of the middle-third (50\%) and posterior wall of the upper-third $(48.1 \%)$. 
Table 3. Pathologic diagnoses of 83 patients with gastric subepithelial tumors.

\begin{tabular}{|c|c|c|c|}
\hline & $\begin{array}{c}\text { Total } \\
n=83\end{array}$ & $\begin{array}{l}\text { ESD Only } \\
\quad n=56\end{array}$ & $\begin{array}{c}\text { Backup Surgery } \\
\qquad n=27\end{array}$ \\
\hline \multicolumn{4}{|c|}{ Malignant or malignant potential } \\
\hline GIST (\%) & $39(47)$ & 23 & 16 \\
\hline - $\quad$ Very low risk & $22(26.5)$ & 16 & 7 \\
\hline - $\quad$ Low risk & $12(14.5)$ & 3 & 8 \\
\hline - $\quad$ Intermediate risk & $5(6)$ & 4 & 1 \\
\hline Neuroendocrine tumor & $1(1.2)$ & 1 & 0 \\
\hline $\begin{array}{l}\text { Hyperplastic polyp with focal } \\
\text { high-grade dysplasia }\end{array}$ & $1(1.2)$ & 1 & 0 \\
\hline \multicolumn{4}{|c|}{ Benign } \\
\hline Leiomyoma (\%) & $31(37.4)$ & 25 & 6 \\
\hline Ectopic pancreas & $3(3.6)$ & 1 & 2 \\
\hline Calcifying fibrous tumor & $2(2.4)$ & 1 & 1 \\
\hline Lipoma & $1(1.2)$ & 1 & 0 \\
\hline Inflammatory fibroid polyp & $1(1.2)$ & 1 & 0 \\
\hline Gastritis cystica profunda & $1(1.2)$ & 1 & 0 \\
\hline Plexiform fibromyxoma & $1(1.2)$ & 0 & 1 \\
\hline Elastofibroma & $1(1.2)$ & 1 & 0 \\
\hline Pyloric gland adenoma & $1(1.2)$ & 0 & 1 \\
\hline
\end{tabular}

\section{Values are $n(\%)$.}

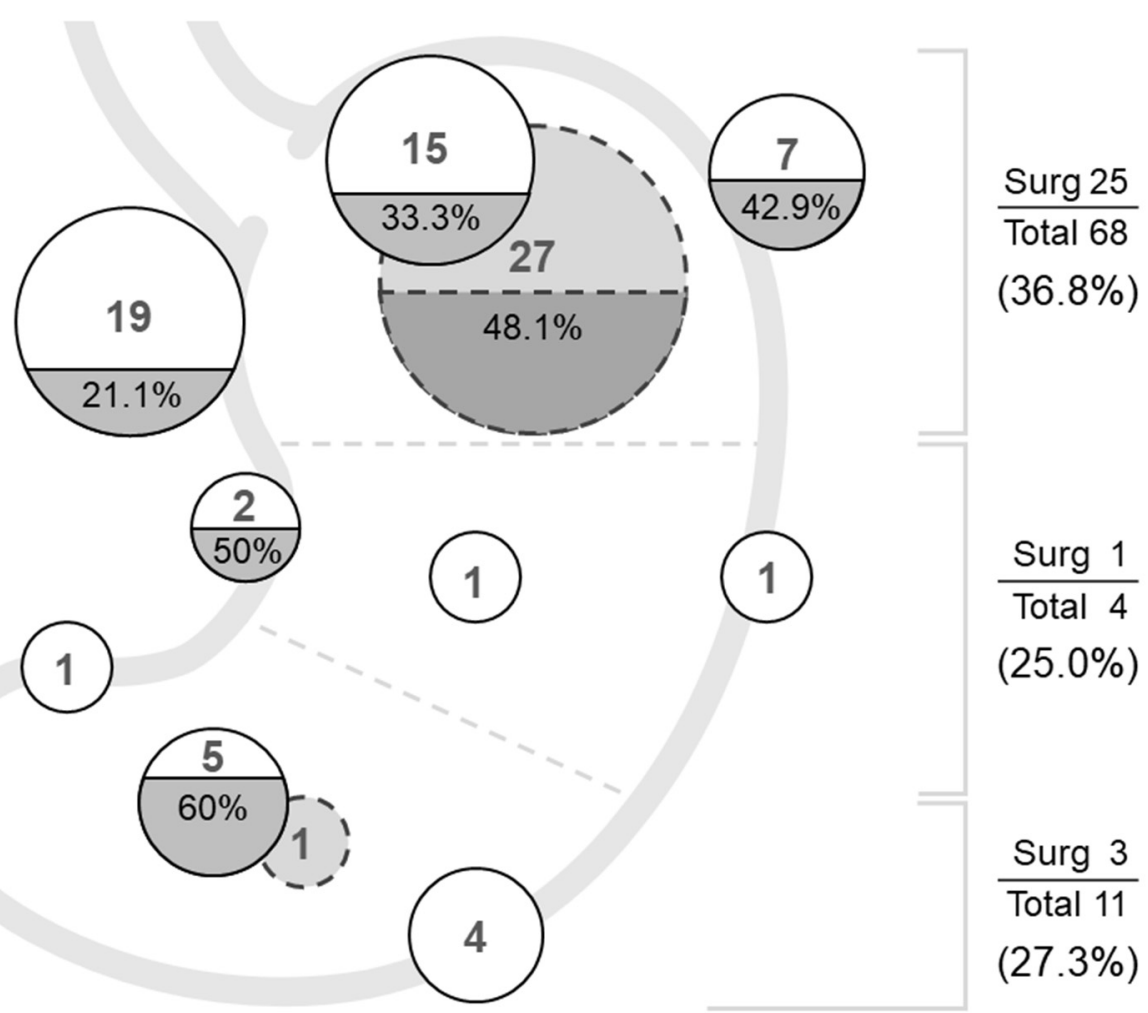

Figure 5. The location of the tumors and the percentage of the patients requiring surgery. 


\section{Discussion}

Among 83 patients who underwent endoscopic resection for gastric SETs at the operation theater, 27 patients (32.5\%) underwent backup laparoscopic surgery, and the most common indication was incidental perforation (96.3\%). Our study demonstrated that gastric SETs highly selected for surgical intervention were mainly located in the upperthird stomach $(81 \%)$ with size $\leq 2 \mathrm{~cm}(69.9 \%)$ and deep to the MP layer $(92.8 \%)$. The risk factor for backup surgery was tumors with exophytic growth. Although there were limited cases in this study, tumors at the anterior wall and at the lesser curvature side were also considered. The ER-only group had shorter duration of procedure times (60 min vs. $185 \mathrm{~min}, p<0.0001$ ) and length of stay ( 5 days vs. 7 days, $p<0.0001)$ but also a higher percentage of overall morbidity with grade III occurred $(7.1 \%$ vs. $0 \%, p=0.1571)$. Five cases $(6 \%)$ developed delayed perforation, and two patients $(2.4 \%)$ underwent emergent laparoscopic surgery with uneventful recovery.

In our study, we modified the LECS procedure and adopted a novel strategy of a minimally invasive procedure that these patients received for endoscopic resection for gastric SETs under general anesthesia with backup laparoscopic surgery in the operation theater. For these selected patients, they declined either periodical surveillance of their SETs or laparoscopic resection and preferred this minimally invasive approach. Additionally, endoscopic resection is deemed to require general anesthesia to provide a more comfortable and safer environment because the endoscopist might have difficulty in approaching and managing the SETs considering endoscopic angulation and patient's uncooperative status. Maintaining airway patency and avoiding aspiration pneumonia in the case of upper GI bleeding during endoscopic resection is another concern for safety. Once the endoscopist could not handle the incidental gastric perforation even after endoscopic repairing, the surgeon could take over the procedure without transportation between the endoscopy room and the operation room and avoid aggravating the risk of hemorrhagic shock or sepsis. Although LECS carries a risk of gastric content spillage and peritoneal seeding of tumor cells due to an intentional gastric perforation, the endoscopists attempted to remove the gastric SETs with R0 resection and the laparoscopists could efficiently clean up the perforation site without further contaminated fluid spreading. Most tumors were retrieved perorally. Neither intra-abdomen abscess postoperatively nor peritoneal seeding of tumor cell were reported during long-term surveillance. Thus, we believed some highly selected patients could benefit from this procedure.

With the concept and advances in LECS [7-11] by a multidisciplinary team, we modified and simplified the backup surgery after endoscopic resection [31] regardless of tumor location. Although a previous retrospective study demonstrated that laparoscopic wedge resection could also treat tumors in an unfavorable location in the lesser curvature or the posterior wall of the gastric body, fundus, and antrum [32], different methods with endoscopic submucosal tunneling [18], laparoscopic transgastric approach [32,33], and anatomic gastrectomy [34] have been reported to avoid lumen stenosis in tumors located near the gastroesophageal junction or the prepyloric area. In our study, once the tumor was easily identified after incomplete ER, the surgeon completed resection using a laparoscopic stapling device and adjusted to the transverse direction of the stomach in the junction area to minimize the resected volume and preserve the greatest function. Most patients were able to attempt an oral diet on postoperative day 3, and none of them had gastroesophageal junction stenosis or gastric outlet obstruction during long-term surveillance. This minimally invasive method is safe and feasible for the management of tumors at unfavorable locations without requiring anatomic gastrectomy. Furthermore, 27 patients received backup surgery in our study with the mean (standard deviation [SD]) 194.5 (67.8) min of operation time and the mean (SD) 7.3 (1.2) days of postoperative hospital stay, and no patients occurred complications above Clavien-Dindo grade III. Compared to a retrospective multicenter study from Japan [35], 126 patients received LECS for gastric SMT between October 2007 and December 2011 with the mean (SD) 190.2 (66.8) min of operation time and the mean (SD) 9.8 (10.1) days of postoperative hospital stay. Two patients (1.6\%) 
had major morbidities with Clavien-Dindo grade IIIb/IVa due to leakage. Although a relatively small sample size in our study, surgical outcomes of those patients receiving backup surgery was comparable to the previous study with satisfactory outcomes.

In our study, the incidental perforation rate after endoscopic resection was $31.3 \%$. In a review of 18 articles, the perforation rate was 3.02\% after ESD and $98.8 \%$ of patients recovered under different methods of endoscopic repair without surgical intervention [36]. In two retrospective studies of ESD for gastric SETs, risk factors for incomplete resection included tumors in the upper-third stomach, tumors $>2 \mathrm{~cm}$, and tumors originating from the MP layer [23,24]. The review study, which encompassed the field of early gastric cancer, further described other risk factors of intraoperative perforation, including location in the middle third, greater curvature and remnant stomach, tumor size, invasion depth, and submucosal fibrosis [36]. In our study with similar results, $81.9 \%$ of tumors were located in the upper-third stomach with a slightly higher percentage of $85.2 \%$ in the surgery group; $69.9 \%$ of tumors had a size of no more than $2 \mathrm{~cm}$ with a higher percentage of $75 \%$ in the ESD-only group; and $92.8 \%$ of tumors were located deep to the MP layer with a high percentage of $100 \%$ in the surgery group. No statistical difference was noted, probably because these cases were highly selected by the endoscopists in this setting. For tumors located in the upper-third stomach, the overall surgery rate was $36.8 \%$, comprising a backup surgery rate of $33.8 \%$ and a delayed surgery rate of $3 \%$. All tumors with exophytic growth necessitated a backup surgery. Thus, we would recommend laparoscopic wedge surgery for tumors with exophytic growth patterns and concern surgery backup for ER, while the tumor is located at the upper-third stomach and deep to the MP layer.

Our study reported five cases $(6 \%)$ of delayed perforation and two patients $(2.4 \%)$ requiring emergent laparoscopic surgery. From the review study, a low incidence rate of delayed perforation was reported to be $0.04-0.7 \%$ after gastric endoscopic resection [36], and most patients could be treated successfully with conservative care. Rare cases required emergent surgery at a rate of $0.043-0.45 \%$ within $1-2$ days, with the most common indication being peritonitis [37-41]. Operation methods included simple closure, omentoplasty, and gastrectomy with hospital stays that ranged from 12-33 days [37,41]. In our study, all patients with delayed perforation had endoclipping during ER and developed symptoms within 2 days after ER, with a hospital stay of 8-9 days. Two patients underwent emergent laparoscopic gastrectomy with indications of internal bleeding and peritonitis, respectively. Previous studies reported that the risk factors of delayed perforation include tumor location in the upper-third stomach [41,42], prolonged procedure time [39,41,43], and exposure of the MP layer [43]. In our study, four patients had tumors located in the upper-third stomach and three patients had tumor depth at the MP layer, but all had a procedure time of less than $2 \mathrm{~h}$. The mechanism of delayed perforation might be explained by ischemia changes [37,39,40,42] and transmural air leak [43]. The upper-third stomach, with a relatively thin wall and larger diameter of the submucosal arteries, was vulnerable to extensive submucosal dissection and repeated hemostasis by electrocautery, which might cause ischemia change and gastric wall necrosis. Frequent bleeding and impaired endoscopic view prolonged the procedure time, resulting in increased intragastric pressure, reduced intramural blood flow, and aggravated ischemia change. In addition, exposure or slight damage of the MP with potential transmural burn during ESD could result in intra-abdominal transmural air leaks. Once the perforation hole is embedded into the surrounding fat tissue, hemostasis with thermal injury to the peripheral vessels might cause delayed bleeding. Although two experienced endoscopists in our procedure minimized the risk of procedure time, other risk factors including tumor location in the upper-third stomach, tumor depth to the MP layer, and suspected perforation with endoclipping used during ER reminded us of timely recognition and effective management for delayed perforation in the previous two days after ER.

GISTs, accounting for $47 \%$ of all resected gastric SETs in this study, are the primary targets of treatment. However, GISTs are often difficult to differentiate from non-neoplastic lesions based on endoscopic sonography. Laparoscopic surgical resection is recommended 
for GISTs less than $5 \mathrm{~cm}$ and in a favorable location [5,32,44], while recent studies have reported that endoscopic resection is also feasible in a less invasive way [45-47]. Considering the malignant potential of GISTs [48,49], the US National Comprehensive Cancer Network and Japanese guidelines recommend either endoscopic or laparoscopic resection for tumors $<2 \mathrm{~cm}$ if they are symptomatic or have high-risk features with rapid growth, ulceration, irregular margins, or heterogeneous echo patterns $[5,6]$. Recent retrospective studies found that $1.4 \mathrm{~cm}$ was an appropriate cutoff tumor size for small GISTs due to their potential for rapid tumor progression [50]. Endoscopic resection for small GISTs $<2 \mathrm{~cm}$ is also safe and effective, which could confirm the diagnosis, improve the symptoms, reduce psychological pressure, and achieve complete cure [51]. Thus, some patients in our study preferred resection over long-term periodic surveillance. For GIST originating from the MP layer, receiving ER with backup surgery was safe and effective for patients in our setting. Long-term surveillance with a mean duration of 19.5 months was performed, and no recurrence was detected.

Our study has some limitations. First, the study was conducted retrospectively at a single center. Second, a relatively small sample size was analyzed because we focused on the patients who declined periodical surveillance of their SETs and laparoscopic resection. Although these studied populations compromised the minority of the patients with gastric SET, the current study is valuable in providing more information regarding the outcomes after endoscopic resection with backup laparoscopic surgery for patients who prefer a less invasive approach for tumor resection. Third, patients who underwent ER for tumors in the superficial submucosal layer (such as neuroendocrine tumor) in the endoscopic room were not included in this database. Selection bias resulted in the majority of tumors being located in the upper-third stomach and origin from the MP layer, which were considered risk factors for incidental perforation after ER. The rate of incidental perforation after ER requiring backup surgery and delayed perforation might be overestimated in this setting compared to other studies. Although there were limited cases in the other sites, our procedure could be applied to wherever the tumor was located in the stomach. Fourth, this study focused on gastric SETs, and SETs in the duodenum or esophagus were not investigated in the present study. Fifth, with the development of ER techniques, endoscopic submucosal tunneling was applied to eight cases with tumors located in the cardiac area, and none of them required further surgery. Procedure-related factors concerning different methods of ER techniques were not discussed in this study and wait for further analysis. Sixth, we lacked the data of those patients who received laparoscopic surgery for gastric SETs in our institution. Further research is required to investigate the comparison between the group of ER with backup surgery and the group of laparoscopic surgery [52,53].

\section{Conclusions}

Based on our center's experience, gastric SETs with a high probability of surgical intervention are mainly located at the upper-third stomach with size $\leq 2 \mathrm{~cm}$ and deep to the MP layer with a backup surgery rate of $32.5 \%$. As a backup surgery after ER, laparoscopic wedge gastrectomy can be applied to gastric SETs wherever they are located. The ER-only group had shorter duration of procedure times (60 $\mathrm{min}$ vs. $185 \mathrm{~min}, p<0.0001)$ and lengths of stay ( 5 days vs. 7 days, $p<0.0001$ ) but a higher percentage of overall morbidity with grade III ( $0 \%$ vs. $7.1 \%, p=0.1571)$ occurring. Five of 56 patients had delayed perforation within 2 days and two required emergent laparoscopic surgery. Tumor with exophytic growth was the risk factor for backup surgery. Neither recurrence nor gastric stenosis was reported during long-term surveillance. Backup laparoscopic wedge gastrectomy is feasible and effective after incomplete ER for gastric SETs.

Author Contributions: Conceptualization, H.-H.Y., C.-W.Y. and K.-H.L.; data curation, W.-J.C., L.-C.T. and J.L.; formal analysis, W.-J.C. and L.-C.T.; investigation, W.-J.C., L.-C.T. and J.L.; methodology, W.-J.C. and H.-H.Y.; project administration, H.-H.Y., C.-W.Y. and K.-H.L.; resources, H.-H.Y., C.-W.Y. and K.-H.L.; validation, L.-C.T.; visualization, L.-C.T.; writing-original draft, W.-J.C.; writing- 
review and editing, H.-H.Y. and K.-H.L. All authors have read and agreed to the published version of the manuscript.

Funding: The authors have no support or funding to report.

Institutional Review Board Statement: The study was conducted according to the guidelines of the Declaration of Helsinki and approved by the Institutional Review Board of Changhua Christian Hospital (Document number 201022; date of approval, 4 December 2020).

Informed Consent Statement: This retrospective study waived the need for informed consent.

Data Availability Statement: All data generated or analyzed during this study are included in this published article.

Conflicts of Interest: The authors declare no conflict of interest.

\section{References}

1. Hwang, J.H.; Rulyak, S.D.; Kimmey, M.B. American Gastroenterological Association Institute technical review on the management of gastric subepithelial masses. Gastroenterology 2006, 7, 2217-2228. [CrossRef] [PubMed]

2. Cho, J.W.; Korean ESD Study Group. Current guidelines in the management of upper gastrointestinal subepithelial tumors. Clin. Endosc. 2016, 3, 235-240. [CrossRef]

3. Miettinen, M.; Lasota, J. Gastrointestinal stromal tumors (GISTs): Definition, occurrence, pathology, differential diagnosis and molecular genetics. Pol. J. Pathol. 2003, 1, 3-24.

4. Casali, P.G.; Abecassis, N.; Aro, H.T.; Bauer, S.; Biagini, R.; Bielack, S.; Bonvalot, S.; Boukovinas, I.; Bovee, J.V.M.G.; Brodowicz, T.; et al. Gastrointestinal stromal tumours: ESMO-EURACAN clinical practice guidelines for diagnosis, treatment and follow-up. Ann. Oncol. 2018, 29, iv68-iv78. [CrossRef] [PubMed]

5. Demetri, G.D.; von Mehren, M.; Antonescu, C.R.; DeMatteo, R.P.; Ganjoo, K.N.; Maki, R.G.; Pisters, P.W.; Raut, C.P.; Riedel, R.F.; Schuetze, S.; et al. NCCN Task Force report: Update on the management of patients with gastrointestinal stromal tumors. J. Natl. Compr. Cancer Netw. 2010, 8, S1-S41. [CrossRef] [PubMed]

6. Koo, D.H.; Ryu, M.H.; Kim, K.M.; Yang, H.K.; Sawaki, A.; Hirota, S.; Zheng, J.; Zhang, B.; Tzen, C.Y.; Yeh, C.N.; et al. Asian consensus guidelines for the diagnosis and management of gastrointestinal stromal tumor. Cancer Res. Treat. 2016, 4, 1155-1166. [CrossRef] [PubMed]

7. Ntourakis, D.; Mavrogenis, G. Cooperative laparoscopic endoscopic and hybrid laparoscopic surgery for upper gastrointestinal tumors: Current status. World J. Gastroenterol. 2015, 43, 12482-12497. [CrossRef]

8. Hiki, N.; Yamamoto, Y.; Fukunaga, T.; Yamaguchi, T.; Nunobe, S.; Tokunaga, M.; Miki, A.; Ohyama, S.; Seto, Y. Laparoscopic and endoscopic cooperative surgery for gastrointestinal stromal tumor dissection. Surg. Endosc. 2008, 7, 1729-1735. [CrossRef]

9. Matsuda, T.; Nunobe, S.; Ohashi, M.; Hiki, N. Laparoscopic endoscopic cooperative surgery (LECS) for the upper gastrointestinal tract. Transl. Gastroenterol. Hepatol. 2017, 5, 40. [CrossRef]

10. Tsujimoto, H.; Yaguchi, Y.; Kumano, I.; Takahata, R.; Ono, S.; Hase, K. Successful gastric submucosal tumor resection using laparoscopic and endoscopic cooperative surgery. World J. Surg. 2012, 2, 327-330. [CrossRef]

11. Nabeshima, K.; Tomioku, M.; Nakamura, K.; Yasuda, S. Combination of laparoscopic and endoscopic approaches to neoplasia with non-exposure technique (CLEAN-NET) for GIST with ulceration. Tokai J. Exp. Clin. Med. 2015, 40, 115-119. [PubMed]

12. Kushnir, V.M.; Keswani, R.N.; Hollander, T.G.; Kohlmeier, C.; Mullady, D.K.; Azar, R.R.; Murad, F.M.; Komanduri, S.; Edmundowicz, S.A.; Early, D.S. Compliance with surveillance recommendations for foregut subepithelial tumors is poor: Results of a prospective multicenter study. Gastrointest. Endosc. 2015, 81, 1378-1384. [CrossRef] [PubMed]

13. Zhou, P.H.; Yao, L.Q.; Qin, X.Y.; Cai, M.Y.; Xu, M.D.; Zhong, Y.S.; Chen, W.F.; Zhang, Y.Q.; Qin, W.Z.; Hu, J.W.; et al. Endoscopic full-thickness resection without laparoscopic assistance for gastric submucosal tumors originated from the muscularis propria. Surg. Endosc. 2011, 9, 2926-2931. [CrossRef] [PubMed]

14. Liu, B.R.; Song, J.T.; Qu, B.; Wen, J.F.; Yin, J.B.; Liu, W. Endoscopic muscularis dissection for upper gastrointestinal subepithelial tumors originating from the muscularis propria. Surg. Endosc. 2012, 11, 3141-3148. [CrossRef] [PubMed]

15. Abe, N.; Takeuchi, H.; Ooki, A.; Nagao, G.; Masaki, T.; Mori, T.; Sugiyama, M. Recent developments in gastric endoscopic submucosal dissection: Towards the era of endoscopic resection of layers deeper than the submucosa. Dig. Endosc. 2013, 25, 64-70. [CrossRef] [PubMed]

16. Kim, H.H. Endoscopic treatment for gastrointestinal stromal tumor: Advantages and hurdles. World J. Gastrointest. Endosc. 2015, 3, 192. [CrossRef]

17. Lu, J.; Jaio, T.; Li, Y.; Zheng, M.; Lu, X. Facilitating retroflexed endoscopic full-thickness resection through loop-mediated or rope-mediated countertraction (with videos). Gastrointest. Endosc. 2016, 1, 223-228. [CrossRef]

18. Shi, D.; Li, R.; Chen, W.; Zhang, D.; Zhang, L.; Guo, R.; Yao, P.; Wu, X. Application of novel endoloops to close the defects resulted from endoscopic full-thickness resection with single-channel gastroscope: A multicenter study. Surg. Endosc. 2017, 2, 837-842. [CrossRef] 
19. Yen, H.H.; Hsu, H.T. Gastric subcentimeter subepithelial tumor: Successful resection with an over-the-scope padlock clip. Endoscopy 2021. [CrossRef]

20. Chiu, P.W.Y.; Yip, H.C.; Teoh, A.Y.B.; Wong, V.W.; Chan, S.M.; Wong, S.K.; Ng, E.K.W. Per oral endoscopic tumor (POET) resection for treatment of upper gastrointestinal subepithelial tumors. Surg. Endosc. 2019, 4, 1326-1333. [CrossRef]

21. Białek, A.; Wiechowska-Kozłowska, A.; Pertkiewicz, J.; Polkowski, M.; Milkiewicz, P.; Karpińska, K.; Ławniczak, M.; Starzyńska, T. Endoscopic submucosal dissection for treatment of gastric subepithelial tumors (with video). Gastrointest. Endosc. 2012, 2, 276-286. [CrossRef] [PubMed]

22. Chu, Y.Y.; Lien, J.M.; Tsai, M.H.; Chiu, C.T.; Chen, T.C.; Yang, K.C.; Ng, S.C. Modified endoscopic submucosal dissection with enucleation for treatment of gastric subepithelial tumors originating from the muscularis propria layer. BMC Gastroenterol. 2012, 12, 124. [CrossRef]

23. Chun, S.Y.; Kim, K.O.; Park, D.S.; Lee, I.J.; Park, J.W.; Moon, S.H.; Baek, I.H.; Kim, J.H.; Park, C.K.; Kwon, M.J. Endoscopic submucosal dissection as a treatment for gastric subepithelial tumors that originate from the muscularis propria layer: A preliminary analysis of appropriate indications. Surg. Endosc. 2013, 9, 3271-3279. [CrossRef] [PubMed]

24. Lee, J.S.; Kim, G.H.; Park, D.Y.; Yoon, J.M.; Kim, T.W.; Seo, J.H.; Lee, B.E.; Song, G.A. Endoscopic submucosal dissection for gastric subepithelial tumors: A single-center experience. Gastroenterol. Res. Pract. 2015, 2015, 425469. [CrossRef]

25. Kim, S.Y.; Kim, K.O. Management of gastric subepithelial tumors: The role of endoscopy. World J. Gastrointest. Endosc. 2016, 8, 418-424. [CrossRef]

26. Tan, Y.; Tan, L.; Lu, J.; Huo, J.; Liu, D. Endoscopic resection of gastric gastrointestinal stromal tumors. Transl. Gastroenterol. Hepatol. 2017, 2, 115. [CrossRef]

27. Oda, I.; Suzuki, H.; Nonaka, S.; Yoshinaga, S. Complications of gastric endoscopic submucosal dissection. Dig. Endosc. 2013, 25, 71-78. [CrossRef]

28. Saito, I.; Tsuji, Y.; Sakaguchi, Y.; Niimi, K.; Ono, S.; Kodashima, S.; Yamamichi, N.; Fujishiro, M.; Koike, K. Complications related to gastric endoscopic submucosal dissection and their managements. Clin. Endosc. 2014, 5, 398-403. [CrossRef]

29. Clavien, P.A.; Barkun, J.; de Oliveira, M.L.; Vauthey, J.N.; Dindo, D.; Schulick, R.D.; de Santibañes, E.; Pekolj, J.; Slankamenac, K.; Bassi, C.; et al. The Clavien-Dindo classification of surgical complications: Five-year experience. Ann. Surg. 2009, 2, 187-196. [CrossRef]

30. Fletcher, C.D.; Berman, J.J.; Corless, C.; Gorstein, F.; Lasota, J.; Longley, B.J.; Miettinen, M.; O'Leary, T.J.; Remotti, H.; Rubin, B.P.; et al. Diagnosis of gastrointestinal stromal tumors: A consensus approach. Hum. Pathol. 2002, 5, 459-465. [CrossRef]

31. Matsuda, T.; Hiki, N.; Nunobe, S.; Aikou, S.; Hirasawa, T.; Yamamoto, Y.; Kumagai, K.; Ohashi, M.; Sano, T.; Yamaguchi, T. Feasibility of laparoscopic and endoscopic cooperative surgery for gastric submucosal tumors (with video). Gastrointest. Endosc. 2016, 1, 47-52. [CrossRef]

32. Liao, G.Q.; Chen, T.; Qi, X.L.; Hu, Y.F.; Liu, H.; Yu, J.; Li, G.X. Laparoscopic management of gastric gastrointestinal stromal tumors: A retrospective 10-year single-center experience. World J. Gastroenterol. 2017, 19, 3522-3529. [CrossRef]

33. Lamm, S.H.; Steinemann, D.C.; Linke, G.R.; Eucker, D.; Simon, T.; Zerz, A.; Stoll, R. Total inverse transgastric resection with transoral specimen removal. Surg. Endosc. 2015, 11, 3363-3366. [CrossRef]

34. Mazer, L.; Worth, P.; Visser, B. Minimally invasive options for gastrointestinal stromal tumors of the stomach. Surg. Endosc. 2021, 3, 1324-1330. [CrossRef]

35. Matsuda, T.; Nunobe, S.; Kosuga, T.; Kawahira, H.; Inaki, N.; Kitashiro, S.; Abe, N.; Miyashiro, I.; Nagao, S.; Nishizaki, M.; et al. Laparoscopic and luminal endoscopic cooperative surgery can be a standard treatment for submucosal tumors of the stomach: A retrospective multicenter study. Endoscopy 2017, 49, 476-483. [CrossRef]

36. Yamamoto, Y.; Kikuchi, D.; Nagami, Y.; Nonaka, K.; Tsuji, Y.; Fujimoto, A.; Sanomura, Y.; Tanaka, K.; Abe, S.; Zhang, S.; et al. Management of adverse events related to endoscopic resection of upper gastrointestinal neoplasms: Review of the literature and recommendations from experts. Dig. Endosc. 2019, 31 (Suppl. 1), 4-20. [CrossRef]

37. Hanaoka, N.; Uedo, N.; Ishihara, R.; Higashino, K.; Takeuchi, Y.; Inoue, T.; Chatani, R.; Hanafusa, M.; Tsujii, Y.; Kanzaki, H.; et al. Clinical features and outcomes of delayed perforation after endoscopic submucosal dissection for early gastric cancer. Endoscopy 2010, 12, 1112-1115. [CrossRef]

38. Kato, M.; Nishida, T.; Tsutsui, S.; Komori, M.; Michida, T.; Yamamoto, K.; Kawai, N.; Kitamura, S.; Zushi, S.; Nishihara, A.; et al. Endoscopic submucosal dissection as a treatment for gastric noninvasive neoplasia: A multicenter study by Osaka University ESD Study Group. J. Gastroenterol. 2011, 3, 325-331. [CrossRef]

39. Yoo, J.H.; Shin, S.J.; Lee, K.M.; Choi, J.M.; Wi, J.O.; Kim, D.H.; Lim, S.G.; Hwang, J.C.; Cheong, J.Y.; Yoo, B.M.; et al. Risk factors for perforations associated with endoscopic submucosal dissection in gastric lesions: Emphasis on perforation type. Surg. Endosc. 2012, 26, 2456-2464. [CrossRef]

40. Ohta, T.; Ishihara, R.; Uedo, N.; Takeuchi, Y.; Nagai, K.; Matsui, F.; Kawada, N.; Yamashina, T.; Kanzaki, H.; Hanafusa, M.; et al. Factors predicting perforation during endoscopic submucosal dissection for gastric cancer. Gastrointest. Endosc. 2012, 6, 1159-1165. [CrossRef]

41. Suzuki, H.; Oda, I.; Sekiguchi, M.; Abe, S.; Nonaka, S.; Yoshinaga, S.; Nakajima, T.; Saito, Y. Management and associated factors of delayed perforation after gastric endoscopic submucosal dissection. World J. Gastroenterol. 2015, 44, 12635-12643. [CrossRef] 
42. Yamamoto, Y.; Nishisaki, H.; Sakai, H.; Tokuyama, N.; Sawai, H.; Sakai, A.; Mimura, T.; Kushida, S.; Tsumura, H.; Sakamoto, T.; et al. Clinical factors of delayed perforation after endoscopic submucosal dissection for gastric neoplasms. Gastroenterol. Res. Pract. 2017, 2017, 7404613. [CrossRef]

43. Onogi, F.; Araki, H.; Ibuka, T.; Manabe, Y.; Yamazaki, K.; Nishiwaki, S.; Moriwaki, H. "Transmural air leak": A computed tomographic finding following endoscopic submucosal dissection of gastric tumors. Endoscopy 2010, 6, 441-447. [CrossRef]

44. Dong, X.; Chen, W.; Cui, Z.; Chen, T.; Liu, X.; Chen, D.; Jiang, W.; Li, K.; Dong, S.; Feng, M.; et al. Laparoscopic resection is better than endoscopic dissection for gastric gastrointestinal stromal tumor between 2 and $5 \mathrm{~cm}$ in size: A case-matched study in a gastrointestinal center. Surg. Endosc. 2020, 11, 5098-5106. [CrossRef]

45. Dai, W.J.; Liu, G.; Wang, M.; Liu, W.J.; Song, W.; Yang, X.Z.; Wang, Q.L.; Zhang, X.Y.; Fan, Z.N. Endoscopic versus laparoscopic resection of gastric gastrointestinal stromal tumors: A multicenter study. Oncotarget 2017, 7, 11259-11267. [CrossRef]

46. Andalib, I.; Yeoun, D.; Reddy, R.; Xie, S.; Iqbal, S. Endoscopic resection of gastric gastrointestinal stromal tumors originating from the muscularis propria layer in North America: Methods and feasibility data. Surg. Endosc. 2018, 4, 17871792. [CrossRef] [PubMed]

47. Pang, T.; Zhao, Y.; Fan, T.; Hu, Q.; Raymond, D.; Cao, S.; Zhang, W.; Wang, Y.; Zhang, B.; Lv, Y.; et al. Comparison of safety and outcomes between endoscopic and surgical resections of small $(\leq 5 \mathrm{~cm})$ primary gastric gastrointestinal stromal tumors. J. Cancer 2019, 17, 4132-4141. [CrossRef] [PubMed]

48. Corless, C.L.; McGreevey, L.; Haley, A.; Town, A.; Heinrich, M.C. KIT mutations are common in incidental gastrointestinal stromal tumors one centimeter or less in size. Am. J. Pathol. 2002, 5, 1567-1572. [CrossRef]

49. Tanaka, J.; Oshima, T.; Hori, K.; Tomita, T.; Kim, Y.; Watari, J.; Oh, K.; Hirota, S.; Matsumoto, T.; Miwa, H. Small gastrointestinal stromal tumor of the stomach showing rapid growth and early metastasis to the liver. Dig. Endosc. 2010, 4, 354-356. [CrossRef]

50. Fang, Y.J.; Cheng, T.Y.; Sun, M.S.; Yang, C.S.; Chen, J.H.; Liao, W.C.; Wang, H.P. Suggested cutoff tumor size for management of small EUS-suspected gastric gastrointestinal stromal tumors. J. Formos. Med. Assoc. 2012, 111, 88-93. [CrossRef] [PubMed]

51. Zhu, L.; Khan, S.; Hui, Y.; Zhao, J.; Li, B.; Ma, S.; Guo, J.; Chen, X.; Wang, B. Treatment recommendations for small gastric gastrointestinal stromal tumors: Positive endoscopic resection. Scand. J. Gastroenterol. 2019, 54, 297-302. [CrossRef] [PubMed]

52. Yen, H.H.; Wu, P.Y.; Su, P.Y.; Yang, C.W.; Chen, Y.Y.; Chen, M.F.; Lin, W.C.; Tsai, C.L.; Lin, K.P. Performance Comparison of the Deep Learning and the Human Endoscopist for Bleeding Peptic Ulcer Disease. J. Med Biol. Eng. 2021. [CrossRef]

53. Yen, H.H.; Wu, P.Y.; Chen, M.F.; Lin, W.C.; Tsai, C.L.; Lin, K.P. Current Status and Future Perspective of Artificial Intelligence in the Management of Peptic Ulcer Bleeding: A Review of Recent Literature. J. Clin. Med. 2021, 10, 3527. [CrossRef] [PubMed] 